\title{
Unusual early symptoms of Parkinson's disease. Why do we need to identify them?
}

\author{
Sintomas incomuns da fase inicial da doença de Parkinson. Por que precisamos \\ identificá-los?
}

Henrique Ballalai Ferraz', Carolina Candeias da Silva

Universidade Federal de São Paulo, Escola Paulista de Medicina, Disciplina de Neurologia, Setor de Distúrbios do Movimento, São Paulo SP, Brasil.

Correspondence:

Henrique Ballalai Ferraz; Rua

Pedro de Toledo, $650 / 1^{\circ}$ andar;

04039-002 São Paulo SP, Brasil.;

E-mail:henrique_ferraz@uol.com.br

Conflict of interest:

There is no conflict of interest to declare.

Received 23 August 2016

Accepted 01 September 2016

\section{(c) BY}

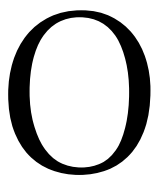

ne of the most frequent situations during the diagnostic phase of Parkinson's disease (PD) is to correctly identify symptoms which could be related to it. The current criteria to diagnose PD are based on the presence of the four classical symptoms: bradykinesia, tremor, rigidity and postural abnormalities. By the other hand, non-classical manifestations such as subtle motor and non-motor symptoms are frequently seen antedating the diagnosis of PD. In this issue, Teive and colleagues report a series of fifteen PD patients with unusual signs and symptoms at the early stage of the disease ${ }^{1}$. This study does not have the aim to identify signs or symptoms that could predict the diagnosis PD or its prodromal phase but calls the attention to apparently unspecific complaints that could be related to bradykinesia, rigidity, fatigue and other motor and non-motor signs of PD.

Some of the unusual characteristics of the series of Teive et al. are not so unusual and has already been described. We can mention color discrimination deficit, Rolex sign, shoulder pain and fatigue. Similar to these somewhat odd manifestations, we can list: a tendency to swim in circles, to write smaller and inclined usually in an upward direction, and early difficulties in coordination that are reported as equipment malfunctioning ${ }^{2}$.

Color discrimination deficit is may be present in PD patients, however the pathophysiology of it is not completely understood. Dopaminergic deficit in the retina and cortical dysfunction associated to cognitive impairment are possible mechanisms involved. Visual symptoms could be present in both early and advanced phases of PD and minor hallucinations have been described in early stages of $\mathrm{PD}^{3}$.

Rhinorrhea is not commonly described as classical non-motor symptom of PD. However, some studies have reported five-time increased prevalence of rhinorrhea in PD patients compared to control ${ }^{4,5,6}$. The relation between rhinorrhea and PD is not clear since it was investigated with non-validated questionnaires or tests. Moreover, it is difficult to exclude other common conditions, like rhinitis and sinusitis or collateral effect of antiparkinsonian drugs as the cause of the rhinorrhea.

PD phenotypes were classically divided into tremor dominant, postural instability and gait difficult (PIGD), or indeterminate subtype. PIGD subtype is marked by bradykinesia, rigidity, axial symptoms and has a higher risk for non-motor symptoms ${ }^{7}$. This could increase the probability to find out more unusual complaints in this subgroup. Non- motor symptoms generally have been described at the advanced phase of PD, but recent researches revealed that almost $40 \%$ of treated PD and drug naïve patients in the early phase of disease have a severe non-motor symptoms burden ${ }^{8}$.

We need early diagnosis of PD to provide an appropriated treatment of motor and non-motor symptoms, and perhaps in the future, to use a neuroprotective strategy. To address this point, many studies in progress are focusing on pre motor or prodromal symptoms. Recognized prodromal markers are: REM sleep disorder, olfactory loss, constipation, excessive daytime somnolence, symptomatic hypotension, severe erectile dysfunction, urinary dysfunction, and depression 9 . These manifestations can produce subtle symptoms not yet recognized as complaints of the early phase of PD. Teive et al. raised the point and now there is a need of systematic studies with a large number of patients looking for this unusual symptoms. An early and precise diagnosis of PD is one of the challenges of our clinical practice. 


\section{References}

1. Teive HAG, Bertucci Filho DC, Munhoz R. Unusual motor and non-motor symptoms and signs in the early stage of Parkinson's disease. Arq Neuropsiquiatr. 2016;74(10):781-84. doi:10.1590/0004-282X20160126

2. Lees AJ, Hardy J, Revesz T. Parkinson's disease. Lancet. 2009:373(9680):2055-66. doi:10.1016/S0140-6736(09)60492-X

3. Pagonabarraga J, Martinez-Horta S, Fernández de Bobadilla R, Pérez J, Ribosa-Nogué R, Marín J et al. Minor hallucinations occur in drug-naive Parkinson's disease patients, even from the premotor phase. Mov Disord. 2016;31(1):45-52. doi:10.1002/mds.26432

4. Friedman JH, Amick MM, Chou KL. Rhinorrhea and olfaction in Parkinson disease. Neurology. 2008;70(6):487-9. doi:10.1212/01.wnl.0000279380.25130.ce

5. Chou KL, Koeppe RA, Bohnen NI. Rhinorrhea: a common nondopaminergic feature of Parkinson's disease. Mov Disord. 2011;26(2):320-3. doi:10.1002/mds.23366
6. Kano O, Yoshioka M, Nagayama H, Hamada S, Maeda T, Hasegawa T et al. Young Japanese Expert Group for Parkinson's Disease and Movement Disorders:YJ-EXPANDS. Rhinorrhea in Parkinson's disease: a consecutive multicenter study in Japan. J Neurol Sci. 2014;343(1-2):88-90. doi:10.1016/j.jns.2014.05.039

7. Ba F, Obaid M, Wieler M, Camicioli R, Martin WR. Parkinson disease: the relationship between non-motor symptoms and motor phenotype. Can J Neurol Sci. 2016;43(2):261-7. doi:10.1017/cjn.2015.328

8. Zis P, Martinez-Martin P, Sauerbier A, Rizos A, Sharma JC, Worth PF et al. Non-motor symptoms burden in treated and untreated early Parkinson's disease patients: argument for non-motor subtypes. Eur J Neurol. 2015;22(8):1145-50. doi:10.1111/ene.12733

9. Berg D, Postuma RB, Adler CH, Bloem BR, Chan P, Dubois B et al. MDS research criteria for prodromal Parkinson's disease. Mov Disord. 2015;30(12):1600-11. doi:10.1002/mds.26431 